\title{
Treatment patterns and health care resource utilization in a I-year observational cohort study of outpatients with schizophrenia at risk of nonadherence treated with long-acting injectable antipsychotics
}

This article was published in the following Dove Press journal:

Patient Preference and Adherence

6 December 201।

Number of times this article has been viewed

\author{
Miguel Bernardo' \\ Luis San $^{2}$ \\ José M Olivares ${ }^{3}$ \\ Tatiana Dilla ${ }^{4}$ \\ Pepa Polavieja ${ }^{4}$ \\ Inmaculada Gilaberte 4 \\ María Álvarez ${ }^{4}$ \\ Antonio Ciudad ${ }^{4}$ \\ 'Department of Psychiatry, Hospital \\ Clinic, University of Barcelona/ \\ IDIBAPS/CIBERSAM, Barcelona, \\ ${ }^{2}$ Department of Child and Adolescent \\ Psychiatry, Hospital Sant Joan de Déu/ \\ CIBERSAM, Barcelona, ${ }^{3}$ Department \\ of Psychiatry, Complejo Hospitalario \\ de Vigo, Pontevedra, ${ }^{4}$ Department of \\ Clinical Research and Development, \\ Madrid, Spain
}

Purpose: To describe (1) the clinical profiles and the patterns of use of long-acting injectable (LAI) antipsychotics in patients with schizophrenia at risk of nonadherence with oral antipsychotics, and in those who started treatment with LAI antipsychotics, (2) health care resource utilization and associated costs.

Patients and methods: A total of 597 outpatients with schizophrenia at risk of nonadherence, according to the psychiatrist's clinical judgment, were recruited at 59 centers in a noninterventional prospective observational study of 1-year follow-up when their treatment was modified. In a post hoc analysis, the profiles of patients starting LAI or continuing with oral antipsychotics were described, and descriptive analyses of treatments, health resource utilization, and direct costs were performed in those who started an LAI antipsychotic.

Results: Therapy modifications involved the antipsychotic medications in $84.8 \%$ of patients, mostly because of insufficient efficacy of prior regimen. Ninety-two (15.4\%) patients started an LAI antipsychotic at recruitment. Of these, only 13 (14.1\%) were prescribed with first-generation antipsychotics. During 1 year, $16.3 \%$ of patients who started and $14.9 \%$ of patients who did not start an LAI antipsychotic at recruitment relapsed, contrasting with the $20.9 \%$ who had been hospitalized only within the prior 6 months. After 1 year, $74.3 \%$ of patients who started an LAI antipsychotic continued concomitant treatment with oral antipsychotics. The mean (median) total direct health care cost per patient per month during the study year among the patients starting any LAI antipsychotic at baseline was $€ 1,407$ (€897.7). Medication costs (including oral and LAI antipsychotics and concomitant medication) represented almost $44 \%$, whereas nonmedication costs accounted for more than $55 \%$ of the mean total direct health care costs.

Conclusion: LAI antipsychotics were infrequently prescribed in spite of a psychiatristperceived risk of nonadherence to oral antipsychotics. Mean medication costs were lower than nonmedication costs.

Keywords: health care costs, depot preparations, medication adherence

\section{Introduction}

Deviation from maintenance antipsychotic therapy remains a recurrent problem in the treatment of schizophrenia, ${ }^{1}$ represents a major difficulty in the management of the disease, and jeopardizes the achievement of relevant clinical outcomes. ${ }^{2-5}$ Long-acting injectable (LAI) antipsychotics were developed specifically to promote adherence and enhance relapse prevention. ${ }^{6}$ Despite 50 years of clinical experience,
Department of Clinical Research an Development, Lilly SA, Avenida de la Industria 30, 28108, Alcobendas, Madrid, Spain

Tel +34 9l 6233570

Fax +34916633471

Email ciudad_antonio@lilly.com 
the knowledge base for examining their potential gains over oral antipsychotics remains inconclusive $e^{7-10}$ and their use is confined to those patients who have suffered multiple relapses within the context of repeated episodes of nonadherence with antipsychotic medication. ${ }^{11}$

Among other factors, the limited availability of secondgeneration LAI formulations ${ }^{12}$ and their high purchase $\operatorname{costs}^{13}$ have been commonly cited as reasons hampering LAI antipsychotic prescription. Currently, when the spectrum of second-generation LAI antipsychotics is growing after years of experience with risperidone as the single novel agent available, updated data on the clinical use of LAI antipsychotics, and the associated health care costs, are welcome.

The present paper reports the results of a naturalistic prospective research done in a cohort of outpatients with schizophrenia whose treatment was modified because of a physician-perceived risk of nonadherence to oral antipsychotic therapy. Although this study put emphasis on evaluating the impact of therapeutic modifications on clinical outcomes in these patients, it also featured the secondary objective of providing comprehensive observational data on how LAI antipsychotics are initiated, what health care resources are utilized, and the total direct health care costs incurred by patients with schizophrenia switched to LAI antipsychotics. This article reports and comments the post hoc analyses and results related to this secondary objective.

\section{Material and methods Design and patients}

This article concerns a post hoc exploratory analysis of the data collected in a 1-year prospective observational study of outpatients with schizophrenia according to the Diagnostic and Statistical Manual of Mental Disorders, Fourth Edition, Text Revision criteria who were considered to be at risk of nonadherence to oral antipsychotic medication by their treating psychiatrists. The primary objective was to evaluate the time to relapse in these patients undergoing any modification of their therapy, ${ }^{14}$ but this study also aimed to assess how LAI antipsychotics are started and used. The aforementioned post hoc analyses involved the description of the resources utilized and the direct health care costs of patients as a result of therapeutic challenges related to adherence issues after starting treatment with LAI antipsychotics. Results of these analyses are also provided.

Patients were recruited on the basis of a modification of their therapy related to a psychiatrist-perceived risk of nonadherence to oral antipsychotic medications, according to their best clinical judgment. To homogenize their criteria, psychiatrists were asked to identify one or more of the following four features related to nonadherence in each patient: (1) poor insight, defined as a general total score $\geq 4$ on the Scale to Assess Unawareness of Illness in Mental Disorders (SUMD); ${ }^{15}$ (2) a negative attitude toward pharmacotherapy, defined as a score $<0$ in the 10-item Drug Attitude Inventory (DAI-10); ${ }^{16}$ (3) documented history of nonadherence; or (4) lack of efficacy (documented clinical instability in the prior 6 months) or inadequate tolerability of current treatment. Therapy modifications could be either a dose adjustment; change or addition in antipsychotic pharmacotherapy; any modification in the use of other selected concomitant psychotropic drugs commonly prescribed to patients with schizophrenia (anticholinergic, antidepressant, anxiolytic, hypnotic, and/or mood stabilizing agents); or the initiation, change, or removal of nonpharmacologic therapies (day center attendance, outpatient support services, rehabilitation, psychotherapy, psychoeducation, and others). Among the changes in antipsychotic medication, the start of an LAI formulation was a possibility. Patients already on LAI antipsychotics were excluded from the study, as it focused on how these medications are started and used afterwards. Therapeutic decisions were not altered due to study participation and were taken at the entire discretion of the treating physician and the patient.

Recruitment took place in 59 mental health community centers in Spain from February to May, 2008. To ensure sample representativity, the number of centers was proportional to the updated regional census. All participants provided written informed consent and the study was approved by an ethical review board following applicable laws and regulations in Spain.

\section{Treatment patterns and clinical evaluations}

After the initial assessment, patients were evaluated again after approximately 3,6 , and 12 months, coinciding with their routine follow-up visits, and when they relapsed or withdrew from the study. The initial assessment included detailed data about therapy modifications for each of the three components mentioned, including the reasons suggested by treating psychiatrists. Information on several known potential risk factors for nonadherence and relapse was collected during a semistructured interview, including sociodemographic data, and psychiatric familial/personal history and comorbidities (Table 1). A battery of clinical instruments was also administered. Among others, these included the Premorbid Adjustment Scale, ${ }^{17}$ the Clinical Global Impression scale-Severity (CGI-S), ${ }^{18}$ the DAI-10, and the SUMD. Total scores below and above 0 in the DAI-10 
Table I Subjects' baseline characteristics according to prescription of long-acting antipsychotics

\begin{tabular}{|c|c|c|c|}
\hline Socio-demographic data & $\begin{array}{l}\text { Long-acting injectable } \\
\text { antipsychotics } \\
(\mathbf{N}=92)\end{array}$ & $\begin{array}{l}\text { Oral antipsychotics } \\
(\mathrm{N}=505)\end{array}$ & $\begin{array}{l}\text { Total } \\
(N=597)\end{array}$ \\
\hline Age, years [mean (SD)] & $39.7(11.1)$ & $40.2(11.2)$ & $40.1(11.1)$ \\
\hline Gender: proportion of males [n (\%)] & $59(64.1)$ & $321(63.6)$ & $380(63.7)$ \\
\hline Marital status: single $[\mathrm{n}(\%)]$ & $63(68.5)$ & $374(74.1)$ & $437(73.2)$ \\
\hline Patients with paid employment [n (\%)] & $16(17.4)$ & $115(22.8)$ & $|3|(21.9)$ \\
\hline Patients receiving social disability benefit [n (\%)] & $54(58.7)$ & $235(46.5)$ & $289(48.4)$ \\
\hline \multicolumn{4}{|l|}{ Clinical data } \\
\hline Age in the first episode, years [mean (SD)] & $24.3(5.4)$ & $25.0(7.2)$ & $24.9(7.0)$ \\
\hline \multicolumn{4}{|l|}{ Duration of untreated psychosis: } \\
\hline$<3$ months [n (\%)] & $19(20.7)$ & $133(26.3)$ & $152(25.5)$ \\
\hline 3 to 12 months [n (\%)] & $34(37.0)$ & $189(37.4)$ & $223(37.4)$ \\
\hline$>12$ months $[\mathrm{n}(\%)]$ & $26(28.3)$ & $114(22.6)$ & $140(23.5)$ \\
\hline Unknown [n (\%)] & $13(14.1)$ & $69(13.7)$ & $82(13.7)$ \\
\hline Had more than 4 prior psychotic episodes [n (\%)] & $45(48.9)$ & $17 \mid(33.9)$ & $216(36.2)$ \\
\hline Familial history of psychiatric disorders [n (\%)] & $42(45.7)$ & $187(37.0)$ & $229(38.4)$ \\
\hline Past or current substance/alcohol use [n (\%)] & $34(37.0)$ & $146(28.9)$ & $180(30.2)$ \\
\hline Hospitalized in prior 6 months [n (\%)] & $23(25.0)$ & $102(20.2)$ & $125(20.9)$ \\
\hline Psychiatric consultations in prior 6 months [mean (SD)] & $5.1(3.4)$ & $4.7(3.4)$ & $4.7(3.4)$ \\
\hline Left duties unattended in prior 6 months [n (\%)] & $81(88.0)$ & $384(76.0)$ & $465(77.9)$ \\
\hline \multicolumn{4}{|l|}{ Scores of clinical instruments } \\
\hline PAS total/possible score [mean (SD)] & $0.6(0.2)$ & $0.5(0.2)$ & $0.6(0.2)$ \\
\hline CGI-S score [mean (SD)] & $4.2(0.8)$ & $4.4(0.8)$ & $4.3(0.8)$ \\
\hline SAPS-SANS total score [mean (SD)] & $19.9(6.3)$ & $18.8(7.0)$ & $19.0(6.9)$ \\
\hline EQ-5D quality of life [mean (SD)] & $61.3(24.1)$ & $57.9(20.5)$ & $58.5(21.1)$ \\
\hline DAI- 10 total score [mean (SD)] & $-1.4(5.2)$ & $0.9(5.2)$ & $0.6(5.3)$ \\
\hline SUMD total score of awareness of disease [mean (SD)] & $6.2(1.6)$ & $6.0(1.7)$ & $6.0(1.7)$ \\
\hline
\end{tabular}

Abbreviations: CGI-S, Clinical Global Impression of Severity; DAl-10, I0-item Drug Attitude Inventory; EQ-5D, EuroQol-5 Dimensions; PAS, Premorbid Adjustment Scale; SAPS-SANS, Abbreviated and combined versions of the Scale for the Assessment of Positive Symptoms and the Scale for the Assessment of Negative Symptoms; SD, standard deviation; SUMD, Scale to Assess the Unawareness of Illness in Mental Disorders.

denoted negative and positive attitudes towards medication, respectively, and patients with a general score $\geq 4$ on the first three items of the SUMD were considered to have a poor level of insight. At follow-up visits, the investigators updated the information on patients' therapy and again administered the clinical instruments. Relapse was defined as the occurrence, at any time during follow-up, of either (1) worsening of psychiatric symptoms that led to a patient's hospitalization or withdrawal from study, or (2) an increase equal to or greater than 1 point in the CGI-S that resulted in a score $\geq 4$.

Patients' patterns of antipsychotic prescription were evaluated to identify those who started treatment with an LAI antipsychotic. The aspects of LAI antipsychotic use evaluated included the proportion of patients concurrently treated with any oral antipsychotic, the duration of this concurrent use pattern, and doses and frequencies of treatment with each antipsychotic drug formulated as LAI.

\section{Resource utilization and cost}

Health care resource utilization was evaluated at each assessment point of the study. Structured abstraction forms were handled to participating psychiatrists to aid in this task.
The information collected included the following three cost components: (1) resources: hospitalizations (psychiatric hospitals and general hospitals), emergency room, psychiatric outpatient consultations, other specialized outpatient consultations, visits to primary care services, skilled nursing facilities; (2) medications: antipsychotics and other psychotropic drugs; and (3) nonpharmacologic therapies: institutional support, assertive community treatment/case management, psychoeducation, psychotherapy, rehabilitation, and management programs for severe mental illness. Nonmedical (informal) direct costs were disregarded. To estimate costs, average unit costs published for Spain, ${ }^{19}$ updated to reflect 2010 rates, were used for each of the resources ascertained; drug acquisition costs were assimilated to the weighted average retail price (plus value-added tax) per $\mathrm{mg}$ in the indication of schizophrenia and were calculated from the 2010 official registered prices. ${ }^{20}$ Another published source was used for the costs of nonpharmacologic therapies, ${ }^{21}$ which was supplemented with a Spanish database..$^{22}$

\section{Data analysis}

All data were analyzed descriptively and used the observations available at each time point (missing data were not imputed). 
This involved the calculation of descriptive statistics (means, medians, standard deviations, interquartile ranges, numbers, and frequencies) for study variables. Patients' baseline characteristics stratified by prescription of LAI antipsychotics were calculated in the whole sample. The doses of each LAI antipsychotic were described throughout the study for patients who started an LAI antipsychotic at baseline. The Kaplan-Meier method was used to describe the time to relapse (in all patients) and the duration of concurrent use of oral antipsychotics with LAI antipsychotics. The Kaplan-Meier method allowed for the estimation of the duration of concurrent use of oral antipsychotics since the start of LAI antipsychotics, regardless of whether it was at baseline or during the study. Utilization of health care resources and mean direct health care cost components were assessed during the study year and expressed as mean and median averaged costs per month per patient for the 92 patients who started an LAI antipsychotic at baseline.
No sample size calculations were made in advance for these analyses. The sample size of the study was calculated at 607 patients, to have sufficient power to analyze the primary objective concerning the time to relapse.

\section{Results}

\section{Patient disposition, characteristics, and therapy modifications at baseline}

Six hundred and twenty-eight patients were recruited. Thirtyone were not analyzed because of the reasons provided in Figure 1. The remaining 597 formed the study cohort; 566 patients completed the study.

Table 1 provides the descriptive statistics of patients' characteristics. They showed an unfavorable clinical profile, featuring severe psychopathology (CGI-S mean: 4.3, higher scores indicating more severity, scoring range: 1-7), frequent substance/alcohol use (30.2\%) and hospitalizations

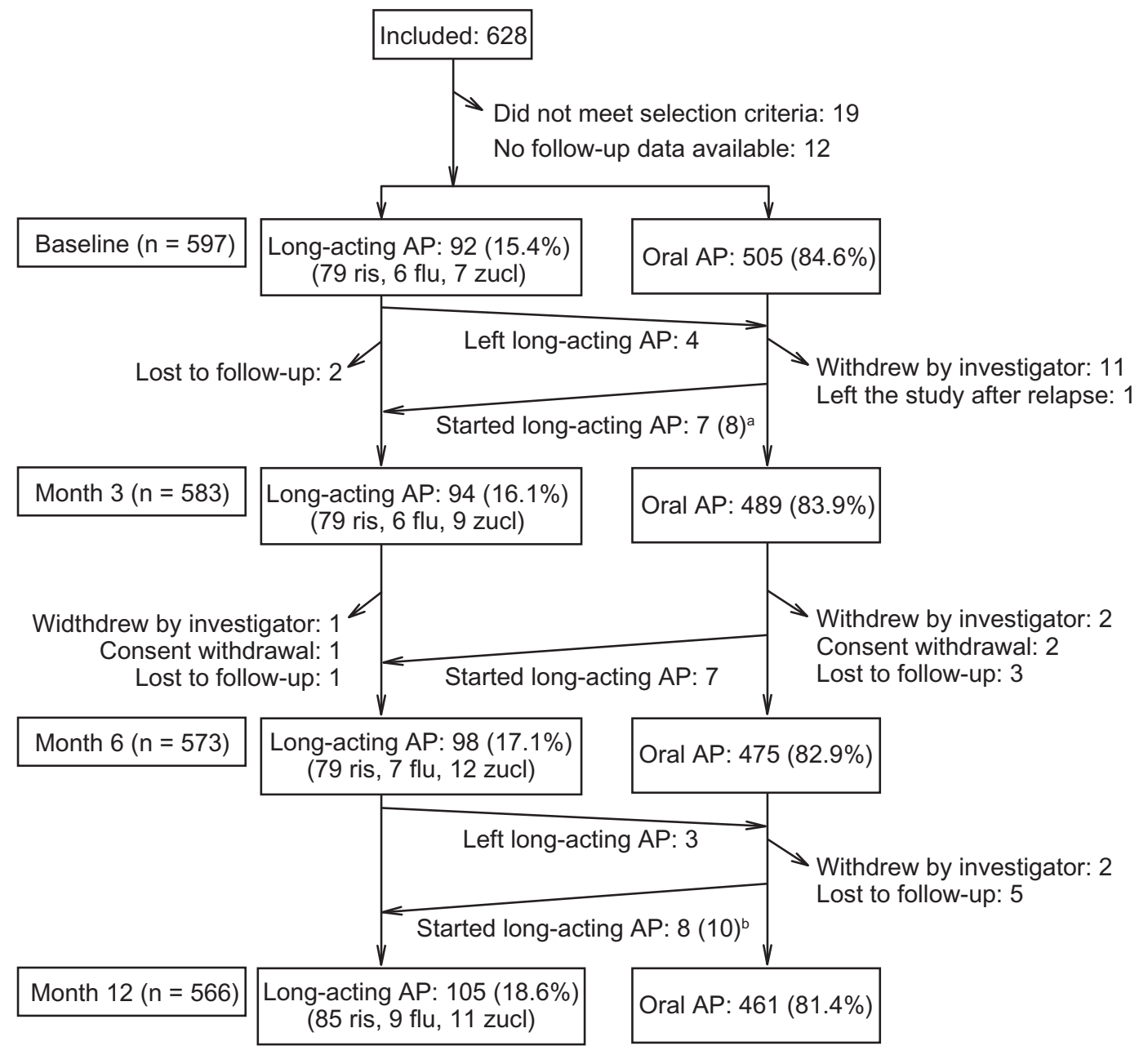

Figure I Patients' disposition throughout the study.

Notes: Total patients starting LAI AP during the study: I 44 (93 ris, 9 flu, I 2 zucl). ane patient left riseperidone LAl to start fluphenazine LAl; bone patient left riseperidone LAI to start Zuclopenthixol LAI and one patient left zuclopenthixol LAl to start risperidone LAI.

Abbreviations: AP, antipsychotics; flu, fluphenazine; ris, risperidone; zucl, zuclopenthixol. 
(20.9\% within the prior 6 months), poor insight (SUMD total: 6.0, higher scores indicating poorer insight, scoring range: $0-9$ ), and quality of life (EQ-5D mean quality of life: 58.5, higher scores indicating better quality of life, scoring range: 0-100). Some of these characteristics, particularly patients' subjective responses (attitudes) toward medications as measured with the DAI-10, differed between patients who started and did not start an LAI antipsychotic at baseline (Table 1).

Antipsychotic drugs were modified in 506 patients $(84.8 \%)$, nonpharmacologic therapies were modified in 190 patients (31.8\%), and concomitant psychotropic medications were modified in 92 patients (15.4\%). The most common reasons alleged for modifying antipsychotic drugs were lack of efficacy $(64.8 \%)$, tolerability issues $(14.2 \%)$, and prior history of nonadherence (13.8\%). Nonpharmacologic therapies were modified because of insufficient effectiveness $(49.0 \%)$, lack of insight $(32.1 \%)$, and documented nonadherence $(11.6 \%)$.

\section{Effectiveness and relapse}

During the study year, the CGI-S scores improved by 0.7 points on average from baseline. In this period, 55 (9.2\%) patients were hospitalized and 90 (15.1\%) relapsed. The survival distribution function of the time to relapse (Figure 2) shows that relapses occurred at a constant pace throughout follow-up. The estimated cumulative incidence of relapse during 1 year, according to the Kaplan-Meier method was $15.2 \%$. This incidence seemed lower than the proportion of patients who had been hospitalized only in the preceding 6 months (20.9\%, Table 1). Relapse affected $16.3 \%$ of patients who started and $14.9 \%$ of patients who did not start an LAI antipsychotic at baseline.

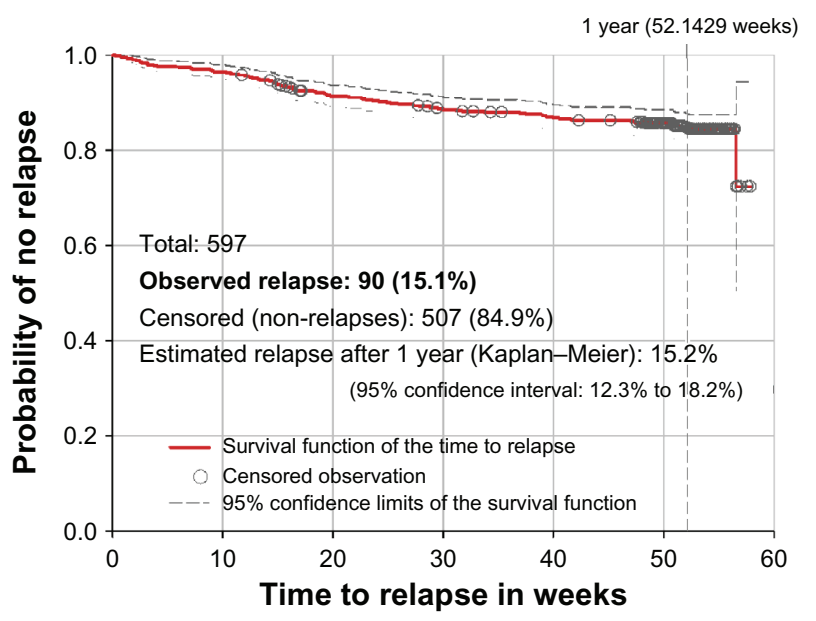

Figure 2 Kaplan-Meier description of the proportion of the sample surviving without relapse during follow-up $(n=597)$.

\section{Use of antipsychotics}

LAI antipsychotics were started at baseline in 92 out of $597(15.4 \%)$ patients. The chosen agent was risperidone in most cases ( 79 patients, $85.9 \%$ ), followed by fluphenazine (6 patients, 6.5\%), and zuclopenthixol (7 patients, 7.6\%). During the study year, 25 patients started (15 risperidone, 4 fluphenazine, and 6 zuclopenthixol) and seven discontinued LAI antipsychotics (Figure 1). Only eight out of these 25 patients $(32.0 \%)$ started the LAI antipsychotic within 1 month after a relapse. Of 31 patients who withdrew prematurely, five were on LAI treatment, giving a total of 105 out of 566 patients $(18.6 \%)$ on LAI antipsychotics by the study end. Throughout the study, the mean modal dose of LAI risperidone was $50 \mathrm{mg}$ every 2 weeks, and about one quarter of patients received higher doses (Figure 3 ). The most common dosing regimens of LAI fluphenazine and zuclopenthixol were $25 \mathrm{mg}$ every 3 weeks and $200 \mathrm{mg}$ every 3 weeks, respectively.

At baseline, 73 out of 92 patients who started an LAI antipsychotic (79.3\%) maintained any concomitant oral antipsychotic drug (62 out of 79 patients started on LAI risperidone, four out of six patients started on LAI fluphenazine, and seven out of seven patients started on LAI zuclopenthixol). This proportion was quite similar 1 year after ( 78 out of 105 patients on LAI antipsychotics, 74.3\%). The 1-year Kaplan-Meier estimates of concurrent use of oral antipsychotics were of 69.1\% with LAI risperidone, 64.8\% with LAI fluphenazine, and $91.7 \%$ with LAI zuclopenthixol (Figure 4). Together with LAI risperidone started at baseline, the oral formulations of risperidone, olanzapine, quetiapine, and aripiprazole (accounting for more than $90 \%$ of concurrent oral antipsychotic medication) were given at median doses of $6 \mathrm{mg} /$ day, $20 \mathrm{mg} /$ day, $1200 \mathrm{mg} /$ day, and $15 \mathrm{mg} /$ day, respectively, throughout the study. Risperidone and olanzapine were also the most common oral agents used concomitantly with LAI fluphenazine and LAI zuclopenthixol, although at lower median doses ( $4 \mathrm{mg} /$ day of risperidone and $10 \mathrm{mg} /$ day of olanzapine).

\section{Health resource utilization and direct health care costs}

Table 2 provides detailed results and the unit costs applied to resource utilization data to calculate direct costs per patient. The mean (median) total health care cost per patient per month during the study year among the 92 patients who started any LAI antipsychotic at baseline was $€ 1407$ (€897.7); this was greater among patients treated with LAI risperidone (€1487 [€998.4]) than with LAI fluphenazine (€938.3 [€147.1]), or LAI zuclopenthixol (€904.3 [€391.3]). 


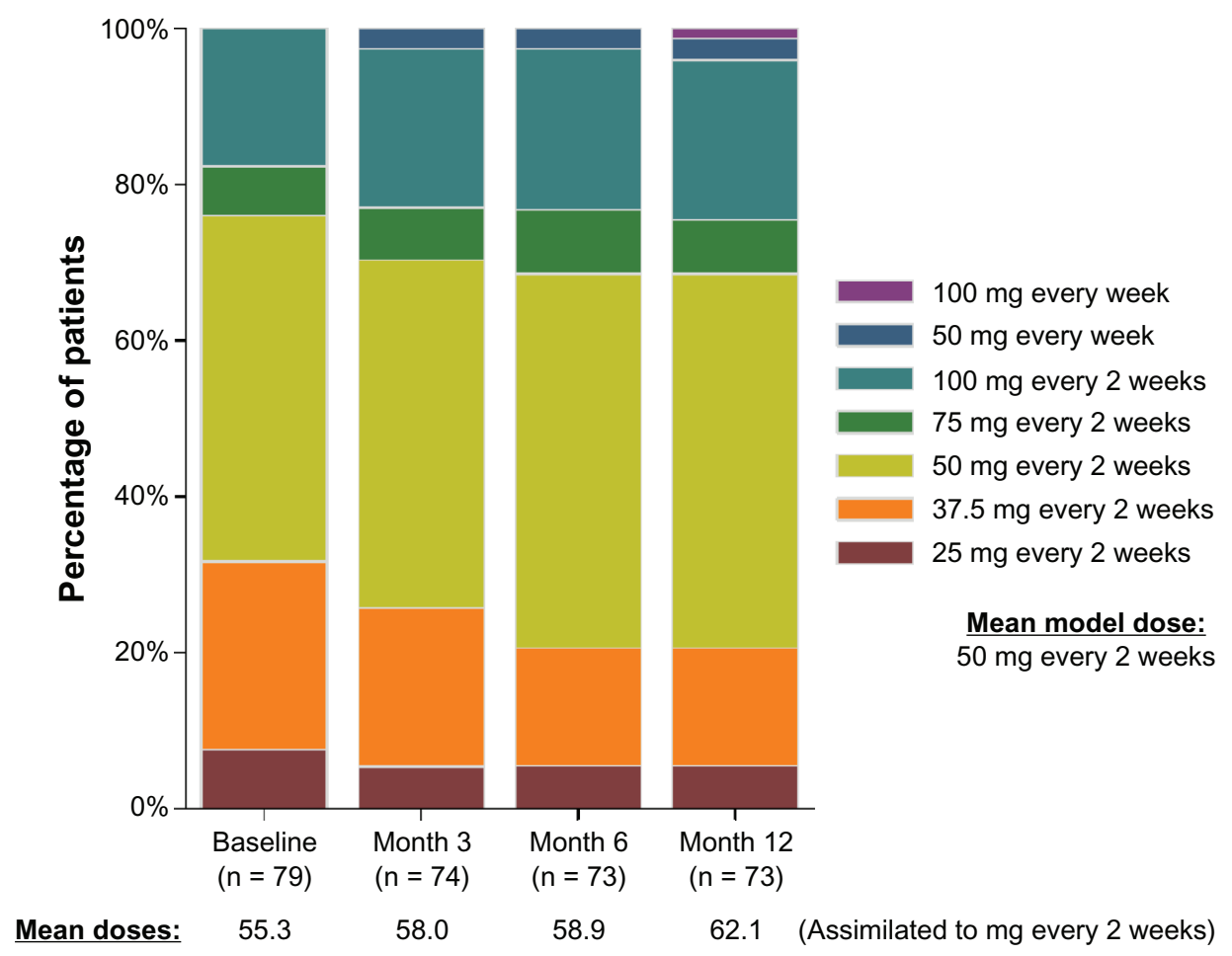

Figure 3 Distribution of the doses of LAl risperidone at each study assessment among patients treated with this medication.

Abbreviation: LAl, long-acting injectable.

Medication costs represented $44.4 \%$ of mean total direct health care costs. LAI risperidone acquisition costs represented $39.4 \%$ of the mean total direct costs incurred by patients treated with this LAI formulation. Those from LAI fluphenazine or LAI zuclopenthixol accounted for no more than $1.2 \%$ of the mean total direct costs, whereas oral supplementation costs accounted for $6.4 \%, 10.8 \%$, and $33.6 \%$ of the mean total direct costs incurred by patients on

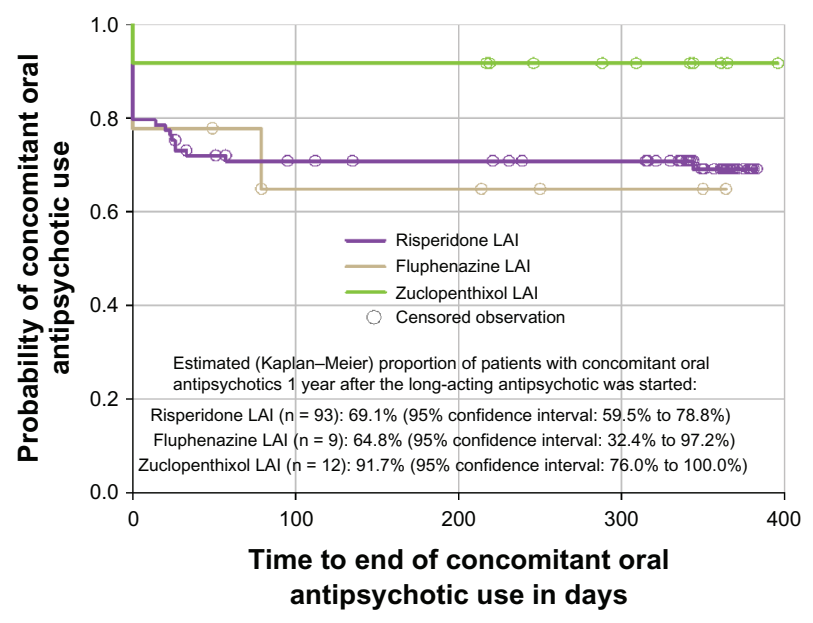

Figure 4 Kaplan-Meier description of the proportion of patients receiving concomitant oral antipsychotics together with LAI antipsychotics, regardless of whether the LAl antipsychotic was started at baseline or during the study. Abbreviation: LAl, long-acting injectable.
LAI risperidone, LAI fluphenazine, and LAI zuclopenthixol, respectively.

Nonmedication costs represented $55.6 \%$ of mean total direct health care costs. Inpatient (general and psychiatric hospitalizations) and outpatient hospitalizations (including institutional support and day hospital stays) costs represented $38.4 \%$ of the mean total direct costs (Table 2, Figure 5). Specifically, institutional support and day hospital stays represented a relevant contribution to mean total direct costs: $€ 263.5$ ( $€ 0$ ) and $€ 208.1$ ( $€ 0)$, despite costs being incurred by only 7 and 18 patients, respectively. However, and despite their high unit costs, inpatient hospitalizations did not account for relevant costs because of their low incidence throughout the study year (10 out of 92 patients, 10.9\%). Table 2 provides a detailed breakdown of resource utilization data and costs.

\section{Discussion}

Patients included in this study showed an unfavorable clinical profile, including factors for bad prognosis that have been consistently associated with nonadherence. Importantly, the intervention made at baseline was associated with improved effectiveness, as denoted by the $9.2 \%$ of patients hospitalized during 1-year follow-up, compared with $20.9 \%$ of patients who had been hospitalized only within the prior 6 months. 
Table 2 Resource utilization and direct health care costs according to prescription of long-acting antipsychotics at baseline

\begin{tabular}{|c|c|c|c|c|}
\hline Antipsychotic drugs $^{a}$ & $\mathbf{N}^{\mathbf{b}}$ & $\begin{array}{l}\text { Average utilization } \\
\text { (services/month) }\end{array}$ & $\begin{array}{l}\text { Unit cost } \\
(€ / \text { service })\end{array}$ & $\begin{array}{l}\text { Average total cost } \\
(€ / \text { patient/month })^{\mathrm{c}, \mathrm{e}}\end{array}$ \\
\hline LAI antipsychotic treatment (any) & 92 & & & $504.5(5 \mid 9.3)[3 \mid 4.7]$ \\
\hline LAl risperidone & 79 & & & $586.5(519.4)[259.5]$ \\
\hline LAl fluphenazine & 6 & & & $\mathrm{I} .3(\mathrm{I} .2)[0.75]$ \\
\hline LAl zuclopenthixol & 7 & & & $10.6(11.9)[5.2]$ \\
\hline Oral antipsychotic treatment & 92 & & & III.6 (36.8) [174.0] \\
\hline \multicolumn{5}{|l|}{ Concomitant psychotropic drugs ${ }^{\mathrm{a}}$} \\
\hline Anticholinergics & & & & $0.2(0.0)[0.8]^{\mathrm{h}}$ \\
\hline Antidepressants & & & & $5.0(0.0)[21.1]^{\mathrm{h}}$ \\
\hline Anxiolytics/hypnotics & & & & $2.1(0.0)[3.8]^{\mathrm{h}}$ \\
\hline Mood stabilizers & & & & $0.8(0.0)[4.0]^{\mathrm{h}}$ \\
\hline Other psychotropics & & & & $1.3(0.0)[5.3]^{\mathrm{h}}$ \\
\hline \multicolumn{5}{|l|}{ Nonpharmacologic therapies } \\
\hline Institutional support & 7 & $20.4(6.0)$ & 169.5 & $263.5(0.0)[959.3]^{\mathrm{h}}$ \\
\hline $\mathrm{ACT} /$ case management & 18 & $4.4(4.7)$ & 40.5 & $34.4(0.0)[108.3]^{\mathrm{h}}$ \\
\hline Group or individual psychoeducation & 11 & $4.1(6.0)$ & 89.2 & $43.7(0.0)[2 \mid 4.0]^{\mathrm{h}}$ \\
\hline Family psychoeducation & 10 & $\mathrm{I} .5(\mathrm{I} .3)$ & 121.7 & $19.9(0.0)[76.8]^{\mathrm{h}}$ \\
\hline Group or individual psychotherapy & 5 & $6.5(8.6)$ & 67.4 & $23.8(0.0)[157.8]^{\mathrm{h}}$ \\
\hline Rehabilitation/occupational support & 15 & $9.5(6.2)$ & 26.6 & $41.1(0.0)[113.8]^{\mathrm{h}}$ \\
\hline Severe mental illness management program & 1 & $1.1(-)$ & 58.2 & $0.7(0.0)[6.6]^{\mathrm{h}}$ \\
\hline \multicolumn{5}{|l|}{ Health care resources } \\
\hline Inpatient hospitalization (general hospital) & 3 & $1.9(1.8)$ & 225.4 & I3.8 $(0.0)[95.6]^{\mathrm{h}}$ \\
\hline Inpatient hospitalization (psychiatric hospital) & 7 & $3.7(3.1)$ & 161.1 & $45.8(0.0)[204.4]^{\mathrm{h}}$ \\
\hline Emergency room visits & 28 & $0.2(0.2)$ & 117.8 & $8.7(0.0)[20.2]^{\mathrm{h}}$ \\
\hline Day hospital & 18 & $6.3(6.2)$ & 169.5 & $208.1(0.0)[620.3]^{\mathrm{h}}$ \\
\hline Psychiatric outpatient consultations & 89 & $0.8(0.3)$ & $69.7,{ }^{f} 42.1^{g}$ & $36.3(37.5)[15.3]$ \\
\hline Other specialized outpatient consultations & 18 & $0.2(0.2)$ & 51.3 & $2.0(0.0)[5.6]^{\mathrm{h}}$ \\
\hline Primary care outpatient consultations & 67 & $0.6(0.4)$ & 18.0 & $8.3(7.3)[8.1]$ \\
\hline Visits to skilled nursing facilities & 89 & $1.9(1.3)$ & 16.8 & $30.7(29.7)[22.1]$ \\
\hline Home visits & 15 & $0.3(0.5)$ & 21.4 & $1.0(0.0)[4.7]^{\mathrm{h}}$ \\
\hline \multicolumn{5}{|l|}{ Total monthly cost per patient } \\
\hline Patients started on any LAI antipsychotic & 92 & & & I 407.0 (897.7) [15|9.0] \\
\hline Patients started on LAI risperidone & 79 & & & $1487.0(998.4)[1543.0]$ \\
\hline Patients started on LAl fluphenazine & 6 & & & $938.3(147.1)[1763.0]$ \\
\hline Patients started on LAI zuclopenthixol & 7 & & & $904.3(391.3)[931.8]$ \\
\hline
\end{tabular}

Notes: aUtilization and unit costs are not expressed because they varied from patient to patient and were calculated on an individual basis according to each patient's pharmacologic treatment; ' number of patients who used the resource at least once during the study year; 'values are mean (median) [standard deviation]; ${ }^{d}$ values are monthly averages among the patients who used the service at least once throughout the study year; ${ }^{e}$ values are averaged for the subgroup of 92 patients who started any LAl antipsychotic treatment at baseline visit; ${ }^{\mathrm{f}}$ cost of the first (initial contact) visit; ${ }^{\mathrm{g}} \mathrm{cost}$ of subsequent (follow-up) visits; ${ }^{\mathrm{h}}$ medians have a value of zero if less than half of the patients used the resource.

Abbreviations: ACT, Assertive Community Treatment; LAl, long-acting injectable.

Although prestudy relapse incidence was not recorded, it is highly probable, based on the comparison of the preposthospitalization rates, that the relapse incidence during the prior year was well above the $15.1 \%$ observed during follow-up. Given the unfavorable profile and the selection procedure, prescription of LAI antipsychotics at baseline (15.4\%) was lower than anticipated. More than 9 in 10 of these LAI prescriptions were of risperidone (the only secondgeneration agent commercially available as LAI when the data were collected), oral antipsychotic supplementation was maintained during 1 year in more than two thirds of patients, and the doses of both oral and LAI antipsychotics were close to their maximum-labeled doses and, therefore, associated with relevant costs. The information available on nonpharmacologic therapies, and health care resource utilization, indicates that the nonmedication direct costs of patients who started therapy with LAI antipsychotics in the year after the initial prescription were substantial, representing $55.6 \%$ of the mean total direct health care costs. Many of these facts are consistent with the relevant literature and have clinical implications.

The prescription of LAI antipsychotics has been considered too low in many studies investigating their use to date, ${ }^{11-13,23}$ which is in agreement with the low utilization in this study. Together with the challenging clinical profile of the patients evaluated, these findings support the generalized 


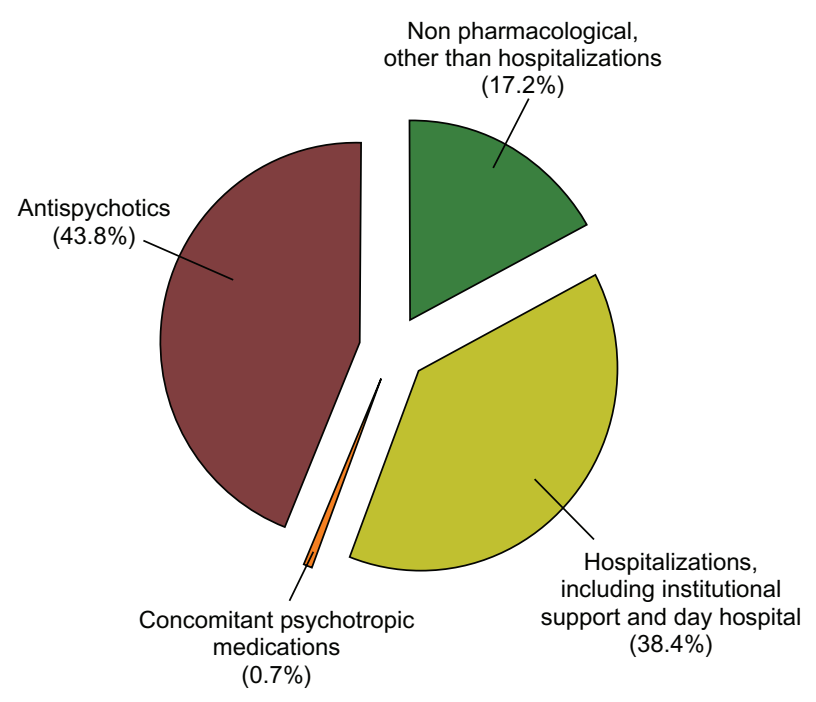

Figure 5 Pie chart showing the breakdown of direct health care costs throughout the study year incurred by patients who started a long-acting injectable antipsychotic at recruitment $(n=92)$.

view among psychiatrists that long-acting antipsychotics should be reserved for a small subgroup of patients and used only after a patient has repeatedly demonstrated difficulty adhering to an oral regimen and has had several relapses. ${ }^{11,24,25}$ The cited studies also included nonadherent patients and, although they were performed in different cultural settings, the proportion of patients changed to long-acting antipsychotics was also low and similar to the $15.4 \%$ observed in this study $\left(10.6 \%{ }^{25}\right.$ and $\left.17.6 \%{ }^{11}\right)$. In this vein, the high doses of LAI antipsychotics and the extensive use of oral antipsychotic supplementation suggest a restrictive use pattern reserved for the patients hardest to treat. ${ }^{26}$ This circumstance might also explain the doses employed; of note, more than one quarter of patients treated with LAI risperidone were above the maximum recommended dose of $50 \mathrm{mg}$ every 2 weeks. ${ }^{27}$

Strikingly, the authors observed similar relapse rates in patients receiving LAI antipsychotics than in patients treated with oral antipsychotics. Some explanations can be cited for this somewhat paradoxical finding. For instance, LAI-treated patients could be in a worse condition than non-LAI patients, but they did not relapse more as they benefited from LAI antipsychotics. Alternatively, nonpharmacologic therapies might also have been effective in preventing relapse in some patients on oral antipsychotics. Importantly, whatever the reason, this study shows that even in the most challenging patients, relapse risk reduction is still clinically feasible if the strategies best suited for each individual are used.

The widespread concurrent use of oral supplementation may also have a clinical reading, in particular considering that risperidone was the agent used in nearly all cases, whose delayed onset of action is known to be inconvenient. ${ }^{28}$ Because oral supplementation therapy should be maintained for at least 3 weeks after starting long-acting risperidone, ${ }^{27,29}$ and because it was reserved for the most troublesome cases, the treating psychiatrists would refrain from ceasing oral therapy once a few weeks had elapsed since the switching, for fear of clinical destabilization of their more challenging patients, ${ }^{30}$ leading to a prolonged polypharmacy. In contrast, a much lower concurrent use of oral antipsychotics with long-acting risperidone has recently been reported after 2 years in the electronic Schizophrenia Treatment Adherence Registry (e-STAR). ${ }^{31}$ Possible reasons for this divergence include differences in disease severity, selection criteria, and LAI risperidone dosing. Patients in the e-STAR were not selected on the basis of nonadherence risk; some were receiving LAI risperidone before recruitment, and started and maintained it at lower doses than in the present study. It remains to be elucidated whether prolonged oral antipsychotic supplementation will be less common when other LAI second-generation antipsychotics that do not require an initial overlap with prior oral therapy are available. The prominent use of risperidone over first-generation LAI antipsychotics also supports the opinion that the unavailability of other second-generation LAI antipsychotics plays a role in their low utilization, ${ }^{32,33}$ as psychiatrists tend to prime the potential advantages of second-generation antipsychotics over the benefits of long-acting formulations. ${ }^{34}$

Few patients started LAI antipsychotics immediately after a relapse. Consistently, psychiatrists questioned about their attitudes toward long-acting antipsychotics, stated that these are not an appropriate option after a relapse, ${ }^{13}$ or for first-episode patients. ${ }^{12,13,26}$ This study has focused on patients undergoing changes of their therapeutic strategy related to nonadherence risk and it cannot address the relevant question of when is the optimal moment for starting long-acting antipsychotic therapy. There are reports suggesting that patients with experience of long-acting antipsychotics have a good opinion on them, ${ }^{35,36}$ yet potential biases of patients established on LAI antipsychotics may distort this judgment. ${ }^{32,37}$ Future research should focus on the use of LAI antipsychotics in stable patients with a favorable disease course, as these have been recently suggested as potential candidates in a survey of psychiatrists' opinions. ${ }^{26}$

One reason alleged to avoid LAI antipsychotics is that they are associated with high treatment costs. ${ }^{13}$ While not opposing this belief, the monthly direct health care cost per patient in this study was substantially higher than the reported average costs of schizophrenia in Spain. ${ }^{19}$ However, the 
present study selected a sample of challenging patients who probably require more resources than the average patient with schizophrenia and, furthermore, we did not account for direct nonmedical costs, which in the cited study represented as much as $47 \%$ of total direct costs. Interestingly, such cost analysis was done prior to licensing of LAI risperidone. In an even more recent report, LAI risperidone proved to be a cost-effective strategy despite the higher drug acquisition costs, because of the considerable reduction in hospital stays. ${ }^{38}$ Relapse is an important predictor of treatment costs for patients with schizophrenia. In the US Schizophrenia Care and Assessment Program (US-SCAP) study, the total direct health care costs of patients without any relapse were lower, but the costs of patients with multiple relapses more than doubled those reported by us. ${ }^{39}$

This research has some limitations. It is based on post hoc analyses and the results should be regarded as exploratory. Comparisons of the outcomes of oral and long-acting second generation antipsychotics is a research priority ${ }^{7}$ but this study cannot provide comparative data as the patients were not randomized to either treatment option. The small number of patients treated with either LAI fluphenazine or LAI zuclopenthixol limits the accuracy of their results, which has precluded a detailed explanation for these patients, compared with that made for patients treated with LAI risperidone. This study did not address some concerns, which in addition to a delayed onset of action, surround the use of long-acting antipsychotics: poor definition of the dose-response relationship, facilities and skills required for their storage and administration, the experience of coercion, the clinical circumstances other than nonadherence and relapse that grant the use of these formulations, or how should the reverse switch (from long-acting to oral) can best be accomplished. Furthermore, this study focused on direct costs and did not therefore collect data on indirect costs, which are substantial in this pathology. ${ }^{19}$ Future research should address these uncertainties and explore the role of long-acting antipsychotics for the maintenance of patients with good levels of insight, who are immersed in the recovery process.

\section{Conclusion}

This study provides current data on the clinical and economic outcomes of patients with schizophrenia at risk of nonadherence in clinical practice in Spain during the 12 months of the study period. It has shown that diminishing relapse in patients with long-standing schizophrenia involving therapeutic challenges related to nonadherence is feasible. It has also confirmed that long-acting antipsychotics are infrequently used.
Most LAI antipsychotic prescriptions were of risperidone, the only atypical antipsychotic available as an LAI when the study was conducted. According to the observed mean total direct health care costs during the study period, medication costs were lower than nonmedication costs, the latter representing more than $55 \%$ of the mean total direct health care costs.

\section{Acknowledgment}

The authors thank Jesús Villoria from Medicxact who provided medical writing services for drafting and submitting this manuscript.

\section{Disclosure}

Miguel Bernardo has participated as a speaker and member of the advisory boards of, and has received grant/research support and honoraria from, Bristol-Myers-Squibb, Eli Lilly, Janssen-Cilag, Mylan, Organon, and Pfizer. Luis San has received grant/research support, received honoraria from, and participated as a speaker and is on the advisory boards of AstraZeneca, Bristol-Myers-Squib, Eli Lilly, Pfizer, Janssen, and Wyeth. José M Olivares has received honoraria from Janssen-Cilag, Lundbeck, AstraZeneca, Eli Lilly, Bristol-Myers-Squibb, Sanofi-Aventis, and Pfizer and has participated in advisory boards organized by Eli Lilly, Janssen-Cilag, and AstraZeneca. Antonio Ciudad, María Álvarez, Tatiana Dilla, Pepa Polavieja, and Inmaculada Gilaberte are full-time employees of Lilly, SA, an affiliate of Eli Lilly and Company.

\section{References}

1. Lacro JP, Dunn LB, Dolder CR, Leckband SG, Jeste DV. Prevalence of and risk factors for medication nonadherence in patients with schizophrenia: a comprehensive review of recent literature. J Clin Psychiatry. 2002;63(10):892-909.

2. Ascher-Svanum H, Faries DE, Zhu B, Ernst FR, Swartz MS, Swanson JW. Medication adherence and long-term functional outcomes in the treatment of schizophrenia in usual care. J Clin Psychiatry. 2006;67(3): 453-460.

3. Law MR, Soumerai SB, Ross-Degnan D, Adams AS. A longitudinal study of medication nonadherence and hospitalization risk in schizophrenia. J Clin Psychiatry. 2008;69(1):47-53.

4. Lieberman JA, Stroup TS, McEvoy JP, et al; Clinical Antipsychotic Trials of Intervention Effectiveness (CATIE) Investigators. Effectiveness of antipsychotic drugs in patients with chronic schizophrenia [published correction appears in N Engl J Med. 2010;363(11):1092-1093]. N Engl J Med. 2005;353(12):1209-1223.

5. Mueser KT, McGurk SR. Schizophrenia. Lancet. 2004;363(9426): 2063-2072.

6. Davis JM, Matalon L, Watanabe MD, Blake L, Metalon L. Depot antipsychotic drugs. Place in therapy. Drugs. 1994;47(5):741-773.

7. Patel MX, Taylor M, David AS. Antipsychotic long-acting injections: mind the gap. Br J Psychiatry Suppl. 2009;52:S1-S4.

8. Rosenheck RA, Krystal JH, Lew R, et al; CSP555 Research Group. Long-acting risperidone and oral antipsychotics in unstable schizophrenia. N Engl J Med. 2011;364(9):842-851. 
9. Leucht C, Heres S, Kane JM, Kissling W, Davis JM, Leucht S. Oral versus depot antipsychotic drugs for schizophrenia-A critical systematic review and meta-analysis of randomised long-term trials. Schizophr Res. 2011;127(1-3):83-92.

10. Tiihonen J, Haukka J, Taylor M, Haddad PM, Patel MX, Korhonen P. A nationwide cohort study of oral and depot antipsychotics after first hospitalization for schizophrenia. Am J Psychiatry. 2011;168(6): 603-609.

11. West JC, Marcus SC, Wilk J, Countis LM, Regier DA, Olfson M. Use of depot antipsychotic medications for medication nonadherence in schizophrenia. Schizophr Bull. 2008;34(5):995-1001.

12. Heres S, Reichhart T, Hamann J, Mendel R, Leucht S, Kissling W. Psychiatrists' attitude to antipsychotic depot treatment in patients with first-episode schizophrenia. Eur Psychiatry. 2011;26(5):297-301.

13. Heres S, Hamann J, Kissling W, Leucht S. Attitudes of psychiatrists toward antipsychotic depot medication. $J$ Clin Psychiatry. 2006;67(12):1948-1953.

14. Ciudad A, San L, Bernardo M, et al. Relapse and therapeutic interventions in a 1-year observational cohort study of nonadherent outpatients with schizophrenia. Prog Neuropsychopharmacol Biol Psychiatry. In press. 2011.

15. Amador XF, Flaum M, Andreasen NC, et al. Awareness of illness in schizophrenia and schizoaffective and mood disorders. Arch Gen Psychiatry. 1994;51(10):826-836.

16. Hogan TP, Awad AG, Eastwood R. A self-report scale predictive of drug compliance in schizophrenics: reliability and discriminative validity. Psychol Med. 1983;13(1):177-183.

17. Cannon-Spoor HE, Potkin SG, Wyatt RJ. Measurement of premorbid adjustment in chronic schizophrenia. Schizophr Bull. 1982;8(3): 470-484.

18. Clinical global impression. In: Guy W, editor. ECDEU Assessment Manual for Psychopharmacology, Revised. Rockville MD: National Institute for Mental Health; 1976:217-222.

19. Oliva-Moreno J, López-Bastida J, Osuna-Guerrero R, MontejoGonzález AL, Duque-González B. The costs of schizophrenia in Spain. Eur J Health Econ. 2006;7(3):182-188.

20. Colleges of Pharmacists Spanish Council. Official medicines catalog. https://botplusweb.portalfarma.com/. Accessed December 15, 2010.

21. Vázquez-Polo FJ, Negrín M, Cabasés JM, Sánchez E, Haro JM, Salvador-Carulla L. An analysis of costs of treating schizophrenia in Spain: a hierarchical Bayesian approach. $J$ Ment Health Policy Econ. 2005;8(3):153-165.

22. Oblikue Consulting SL. Oblikue Consulting eSALUD - Healthcare database on costs, 2008. http://oblikue.com/bddcostes. Accessed November 24, 2010.

23. Shi L, Ascher-Svanum H, Zhu B, Faries D, Montgomery W, Marder SR. Characteristics and use patterns of patients taking first-generation depot antipsychotics or oral antipsychotics for schizophrenia. Psychiatr Serv. 2007;58(4):482-488.

24. Keith SJ, Kane JM, Turner M, Conley RR, Nasrallah HA. Academic highlights: guidelines for the use of long-acting injectable atypical antipsychotics. J Clin Psychiatry. 2004;65(1):120-131.
25. Kelin K, Brnabic AJ, Newton R, et al. Baseline characteristics and initial treatment decisions for patients with schizophrenia at risk of treatment nonadherence. Patient Prefer Adherence. 2010;4:301-311.

26. Heres S, Hamann J, Mendel R, et al. Identifying the profile of optimal candidates for antipsychotic depot therapy A cluster analysis. Prog Neuropsychopharmacol Biol Psychiatry. 2008;32(8):1987-1993.

27. Janssen-Cilag. Risperdal-Consta. Summary of Product Characteristics. http://www.ema.europa.eu/ema/index.jsp?curl=pages/medicines/ human/referrals/Risperdal_Consta/human_referral_000027. jsp\&murl=menus/regulations/regulations.jsp. Accessed February 16, 2011.

28. Eerdekens M, Van Hove I, Remmerie B, Mannaert E. Pharmacokinetics and tolerability of long-acting risperidone in schizophrenia. Schizophr Res. 2004;70(1):91-100.

29. Taylor D. Psychopharmacology and adverse effects of antipsychotic longacting injections: a review. Br J Psychiatry. 2009;195(52):S13-S19.

30. Taylor D, Mir S, Mace S, Whiskey E. Co-prescribing of atypical and typical antipsychotics - prescribing sequence and documented outcome. Psychiatr Bull. 2002;26(5):170-172.

31. Peuskens J, Olivares JM, Pecenak J, et al. Treatment retention with risperidone long-acting injection: 24-month results from the Electronic Schizophrenia Treatment Adherence Registry (e-STAR) in six countries. Curr Med Res Opin. 2010;26(3):501-509.

32. Patel MX, De Zoysa N, Bernadt M, David A. Depot and oral antipsychotics: patient preferences and attitudes are not the same thing. J Psychopharmacol. 2009;23(7):789-796.

33. Patel MX, Nikolaou V, David AS. Psychiatrists' attitudes to maintenance medication for patients with schizophrenia. Psychol Med. 2003; 33(1):83-89.

34. Patel MX, David AS. Why aren't depot antipsychotics prescribed more often and what can be done about it? Adv Psychiatr Treat. 2005; 11(3):203-211.

35. Caroli F, Raymondet P, Izard I, Plas J, Gall B, Delgado A. Opinions of French patients with schizophrenia regarding injectable medication. Patient Prefer Adherence. 2011;5:165-171.

36. Waddell L, Taylor M. Attitudes of patients and mental health staff to antipsychotic long-acting injections: systematic review. Br J Psychiatry Suppl. 2009;52:S43-S50.

37. Burns T. Knowledge about antipsychotic long-acting injections: bridging that gap. Br J Psychiatry Suppl. 2009;52:S5-S6.

38. Olivares JM, Rodriguez-Martinez A, Buron JA, Alonso-Escolano D, Rodriguez-Morales A. Cost-effectiveness analysis of switching antipsychotic medication to long-acting injectable risperidone in patients with schizophrenia: a 12- and 24-month follow-up from the e-STAR database in Spain. Appl Health Econ Health Policy. 2008;6(1):41-53.

39. Ascher-Svanum H, Zhu B, Faries DE, et al. The cost of relapse and the predictors of relapse in the treatment of schizophrenia. BMC Psychiatry. 2010;10:2.
Patient Preference and Adherence

\section{Publish your work in this journal}

Patient Preference and Adherence is an international, peer-reviewed, open access journal focusing on the growing importance of patient preference and adherence throughout the therapeutic continuum. Patient satisfaction, acceptability, quality of life, compliance, persistence and their role in developing new therapeutic modalities and compounds to

\section{Dovepress}

optimize clinical outcomes for existing disease states are major areas of interest. This journal has been accepted for indexing on PubMed Central. The manuscript management system is completely online and includes a very quick and fair peer-review system. Visit http://www.dovepress.com/ testimonials.php to read real quotes from published authors. 